\title{
Is echocardiographic epicardial fat thickness increased in patients with coronary artery disease? A systematic review and meta-analysis
}

\author{
Mohammad Ali Ansari ${ }^{1}$, Mohsen Mohebati ${ }^{2,3}$, Farid Poursadegh ${ }^{4}$, Mahdi Foroughian $^{5}$, Alireza Sepehri Shamloo ${ }^{1}$ \\ 1 Atherosclerosis Prevention Research Center, Department of Cardiovascular Diseases, Faculty of Medicine, \\ Mashhad University of Medical Sciences, Mashhad, Iran \\ ${ }^{2}$ Associate Professor, Metabolic Syndrome Research Center, Faculty of Medicine, Mashhad University of Medical \\ Sciences, Mashhad, Iran \\ ${ }^{3}$ Cardiovascular Research Center, Faculty of Medicine, Mashhad University of Medical Sciences, Mashhad, Iran \\ ${ }^{4}$ Internal Medicine Department, Faculty of Medicine, Mashhad University of Medical Sciences, Mashhad, Iran \\ ${ }^{5}$ Emergency Medicine Department, Faculty of Medicine, Mashhad University of Medical Sciences, Mashhad, Iran
}

Type of article: Meta-analysis

\begin{abstract}
Background: The relation of epicardial fat thickness (EFT) to coronary artery disease (CAD) has recently been reported in multiple studies. Echocardiography is a safe and relatively inexpensive and accessible approach to assess regional EFT, which can be performed easily in many centers.

Objective: To determine the association between echocardiographic EFT and the presence or the absence of CAD.

Methods: This was a systematic review and meta-analysis conducted on literature available in electronic databases up to March 2018. The articles measuring EFT by echocardiography in the right ventricular (RV) free wall were included in the study. The quality of the enrolled items was assessed using the Methodological Index for Non-Randomized Studies (MINORS) checklist. The analyses were performed using the Comprehensive Meta-Analysis version 2 software. Cochran's $\mathrm{Q}$ test and $\mathrm{I}^{2}$ index were used to evaluate heterogeneity.

Results: This meta-analysis was performed on 13 studies involving 2,436 patients (1,622 with CAD, and 814 without CAD). The maximum EFT reported by echocardiography was $12.9 \pm 2.7 \mathrm{~mm}$ in the CAD group and $8.4 \pm 2.5 \mathrm{~mm}$ in the non-CAD group. The minimum EFT reported by echocardiography was $2.2 \pm 1.8 \mathrm{~mm}$ in the CAD group and $1.8 \pm 1.4 \mathrm{~mm}$ in the non-CAD group. The heterogeneity was found among the researched studies $\left(\mathrm{I}^{2}=91.8 \%, \mathrm{p}=0.000\right.$, Q-value $=146.43$, df $\left.[\mathrm{Q}]=12\right)$ using the random effect model. The patients with CAD had a significantly higher echocardiographic EFT than those without $\mathrm{CAD}(\mathrm{SMD}=1.03,95 \% \mathrm{CI}=0.70-1.37, \mathrm{p}=0.000)$.

Conclusion: According to the findings of this meta-analysis, the echocardiographic EFT in the subjects with CAD was significantly higher than that of those without CAD. The measurement of echocardiographic EFT seems to be an acceptable strategy for risk stratification of heart diseases considering ease of use, costeffectiveness and non-exposure characteristics, compared to other imaging interventions.

Keywords: Adipose tissue, Epicardial fat thickness, Echocardiography, Coronary artery disease, Meta-analysis
\end{abstract}

\section{Note:}

This study has followed the Preferred Reporting Items for Systematic Reviews and Meta-Analyses: The PRISMA Statement (http://www.prisma-statement.org). PRISMA is an evidence-based minimum set of items for reporting in systematic reviews and meta-analyses. PRISMA focuses on the reporting of reviews evaluating randomized trials, but can also be used as a basis for reporting systematic reviews of other types of research, particularly evaluations of interventions.

\section{Corresponding author:}

Associate Professor Dr. Mohsen Mohebati, Cardiovascular Research Center, Faculty of Medicine, Mashhad University of Medical Sciences, Mashhad, Iran.

Tel: +98.9153158095, Fax: +98.5138012739, E-mail: mohebatim@mums.ac.ir

Received: May 02, 2018, Accepted: June 04, 2018, Published: September 2018

iThenticate screening: June 05, 2018, English editing: July 06, 2018, Quality control: July 15, 2018

This article has been reviewed / commented by three experts

Funding / research project approval: Mashhad University of Medical Sciences (Ref: 960248, December 26, 2017)

(C) 2018 The Authors. This is an open access article under the terms of the Creative Commons Attribution-NonCommercialNoDerivs License, which permits use and distribution in any medium, provided the original work is properly cited, the use is non-commercial and no modifications or adaptations are made. 


\section{Introduction}

Visceral fat is a significant risk factor for the development of metabolic syndrome and coronary artery disease (CAD) (1). The anatomical and functional proximity of myocardium to its surrounding visceral adipose tissue (VAT) and the metabolic activity of this tissue are some of the reasons for the increase in the importance of studying epicardial fat thickness (EFT) in recent years (2). EFT is a type of VAT that has recently been shown to be related to cardiovascular disease (3). EFT is a visceral fat deposited around the heart and under the visceral layer of the pericardium, and especially around the major epicardial coronary arteries. EFT seems to be associated with coronary artery atherosclerosis via inflammatory and secretory mechanisms of various cytokines (1-4). Echocardiography is a safe and relatively inexpensive and accessible approach to assess regional EFT, which can be performed easily in many centers (5). Typically, the echocardiographic EFT is defined based on the measurement of the low-isoechoic area thickness on the free wall of the right ventricle (RV) in the parasternal long- and short-axis views $(6,7)$. If one can detect the presence of CAD (more than 50\% coronary artery stenosis in angiography) using epicardial and visceral fat status by the non-invasive method of echocardiography, it will be possible to prevent unnecessary invasive angiography in the future (8). Although several meta-analyses have been conducted over recent years on the relationship between EFT and CAD, there are still unanswered questions about the capability of echocardiography in determining the relationship between EFT and CAD $(9,10)$. Recent meta-analysis revealed the findings on the relationship between EFT assessed by computed tomography (CT) and CAD $(11,12)$. Further, a meta-analysis of $\mathrm{Wu}$ et al. reported the association between CAD and EFT regardless of measurement position and tools; however, after the publication of this article, many other studies have also been carried out that have not yet been included in any meta-analysis (10). This study aimed to investigate the association between echocardiographic EFT and the presence or the absence of CAD.

\section{Material and Methods}

\subsection{Protocol}

This systematic review and meta-analysis was conducted by the principles set in the Preferred Reporting Items for Systematic Reviews and Meta-Analyses: the PRISMA Statement.

\subsection{Eligibility criteria and Study selection}

The observational studies evaluating the relationship between EFT and CAD were included in the study. The exclusion criteria were: 1) determination of EFT with tools other than echocardiography, 2) CAD diagnostic standard other than conventional angiography, CT angiography, or MRI angiography, 3) Failure to report EFT as mean and standard deviation between the two groups with and without CAD, 4) the reports of EFT in sites other than the right ventricular free wall, and 5) review articles or case reports. No date restriction was considered for the studies, but those with non-English abstracts and the articles lacking full text or published only as summary in abstract were excluded from the study. Eligible articles were independently checked by two reviewers (Mohammad Ali Ansari and Alireza Sepehri Shamloo) to ensure full compliance with the inclusion and exclusion criteria, and any disagreement was discussed, to be judged and revised.

\subsection{Information sources and Search}

The databases of MEDLINE/PubMed, Scopus, Thomson Reuters Web of Science, Cochrane Library, DARE, Cumulative Index to Nursing and Allied Health Literature (CINAHL) and Google Scholar were searched from inception until March 31, 2018 using the keywords: "Epicardial adipose tissue, Epicardial fat, Subepicardial adipose tissue, Subepicardial fat, Coronary artery disease, Diagnostic techniques and procedures, Myocardial ischemia, Myocardial infarction, Coronary angiography; Acute coronary syndrome, Angina, Stable, Non-invasive methods (Elasticity Imaging Techniques), and Coronary stenosis". The abstracts and titles of articles found in databases were reviewed by two different assessors to exclude non-content related articles. In cases where the excluded studies for each database were not the same, the differences were checked to obtain a similar judgement. Moreover, the references to all related articles were reviewed to be added to our review article if relevant. Gray literature was not assessed in the current study.

\subsection{Data collection process}

The required information was collected for the articles using a data extraction table, including title, name of first author, year of publication, place of study, sample size, retrospective or prospective status of study, diagnostic test method for detecting EFT and CAD, sample size based on the results of angiography, the mean age of the subjects, the frequency distribution of gender, and the mean EFT in the RV free wall in millimeters in both groups with and without CAD. This table was completed by the first reviewer (MAA), and checked and verified by the second one (ASSH). 


\subsection{Quality assessment}

The Methodologic Index for Non-Randomized Studies (MINORS) checklist was used to assess the quality of the articles included in the study (13). MINORS is a valid checklist, with 12 -items, considered to assess the quality of non-randomized observational studies. The items were scored 2 if reported and adequate, 1 in cases of inadequate reporting, and 0 when not reported. The global ideal score was 24 for studies. This checklist was completed separately for each study by two different assessors. In cases where the score calculated for each article by two raters was not the same, the differences were checked to obtain a consensus score.

\subsection{Summary measures and Synthesis of results}

The analyses were performed using the Comprehensive Meta-Analysis version 2 software (Biostat, Englewood, New Jersey). The standardized mean difference (SMD) with 95\% confidence interval (CI) was calculated for EFT between the two groups with and without CAD. The force plate was used to represent the findings of each study and the total findings. Cochran's Q test was applied to evaluate heterogeneity. $\mathrm{P}<0.05$ was considered as the statistical significance level. The $\mathrm{I}^{2}$ index was used to quantify the heterogeneity. The fixed effects model was selected for $\mathrm{I}^{2}$ less than $30 \%$ and the random effects model for $\mathrm{I}^{2}$ more than $30 \%$. Potential sources for heterogeneity were the echocardiographic view, the EFT measurement interval, the criteria used to define the CAD based on the percentage of coronary artery stenosis, and quality of studies based on MINORS. The probability of publication bias was evaluated through Classic Fail-safe N tests, and Orwin's Failsafe-N, Duval and Tweedie's trim-and-fill.

\section{Results}

\subsection{Study selection}

A total of 175 articles were found in databases and search engines (Figure 1). However, 131 articles were omitted after reviewing their title and abstract, and the full text of the remaining 44 items were studied in detail.

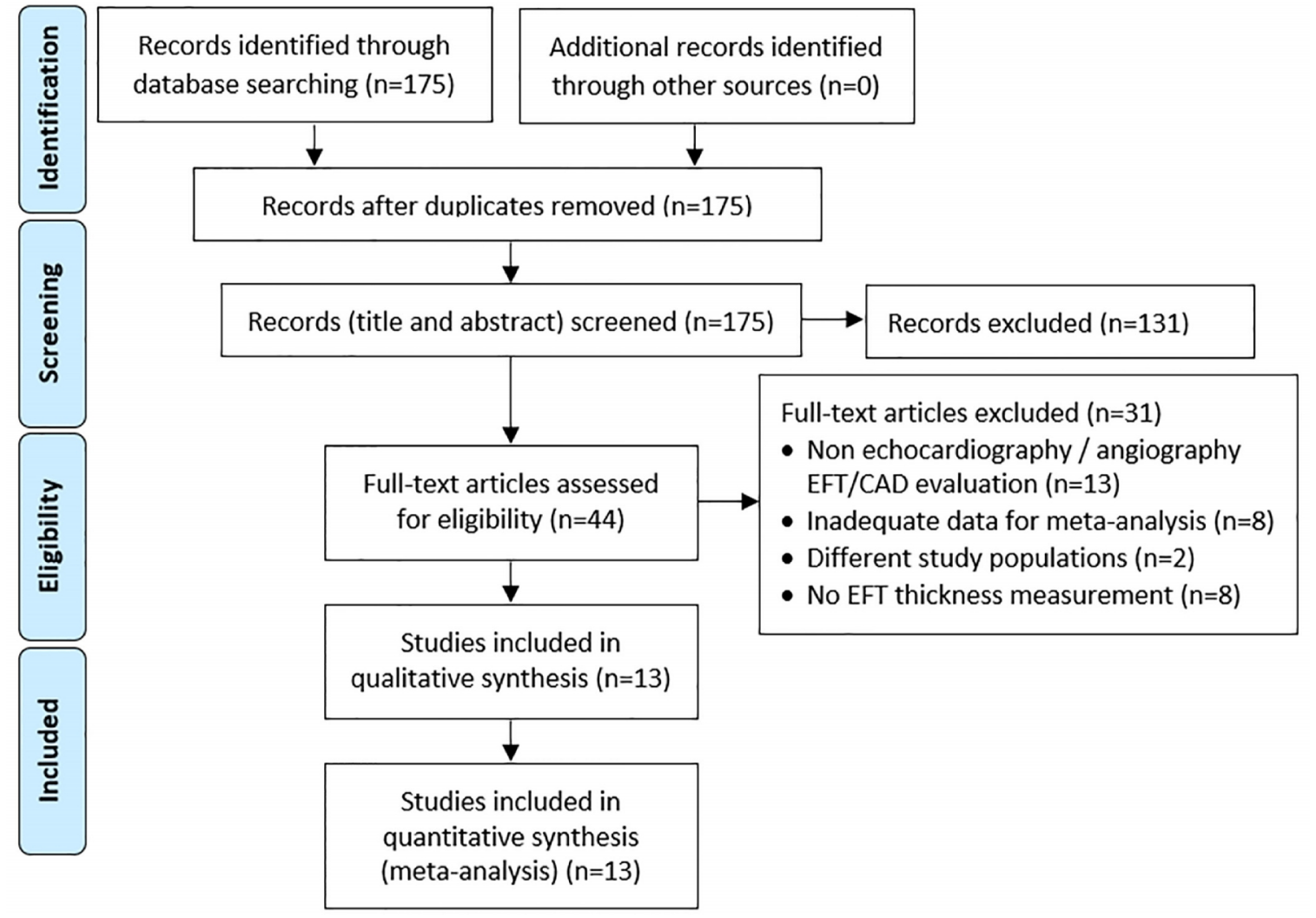

Figure 1. Flow diagram of included studies in the meta-analysis based on PRISMA statement

\subsection{Excluded studies}

Thirty-one studies were excluded for various reasons after reviewing the original text. In 13 studies, the EFT had been measured using a tool other than echocardiography, or CAD had been detected by a non-angiographic method (14-26). In 8 studies, the parameters required to enter meta-analysis were not reported (27-34). In 2 studies, the 
http://www.ephysician.ir

findings related to epicardial thickness had been reported in groups other than CAD and non-CAD, such as coronary artery spasm (35) or carotid stenosis (36). In 8 studies, the numerical values of EFT had not been reported (31, 3642).

\subsection{Study characteristics}

This meta-analysis was performed on 13 studies involving 2,436 patients (1,622 with CAD, and 814 without CAD). In the majority of studies $(\mathrm{n}=10)$, CAD was considered to be in the presence of stenosis in over $50 \%$ of each major coronary arteries; in 2 studies, stenosis was over $75 \%$, and one study did not report the criteria. In all studies, the angiography had been considered as the diagnostic gold standard of CAD, and echocardiography had been employed to determine EFT. The smallest sample size was 40 patients (43), and the largest sample size was 549 patients (44). The first article had been published in 2006 (5) and the latest articles in 2016 (45-47). The majority of studies were conducted in Turkey (Table 1).

Table 1. Characteristics of included studies in the meta-analysis in relation to echocardiographic epicardial fat thickness (EFT) between patients with or without coronary artery disease (CAD)

\begin{tabular}{|c|c|c|c|c|c|c|c|c|c|c|}
\hline $\begin{array}{l}\text { Ref. } \\
\text { no. }\end{array}$ & Location & $\mathrm{n}$ & \multicolumn{2}{|c|}{$\begin{array}{l}\text { CAD group, EFT } \\
\text { Thickness }(\mathrm{mm})\end{array}$} & \multicolumn{2}{|c|}{$\begin{array}{l}\text { Non-CAD group, } \\
\text { EFT Thickness (mm) }\end{array}$} & $\begin{array}{l}\text { Stenosis* } \\
\%\end{array}$ & Echocardiographic view & $\begin{array}{l}\text { Time of EFT } \\
\text { measurement }\end{array}$ & $\begin{array}{l}\text { Quality } \\
\text { Score } \\
(24)\end{array}$ \\
\hline 5 & U.S.A & 139 & 85 & $2.22(1.86)$ & 54 & $2.16(1.77)$ & 50 & Parasternal long- and short axis & End-diastolic & 14 \\
\hline 7 & Turkey & 150 & 100 & $6.9(1.5)$ & 50 & $4.4(0.8)$ & 50 & Parasternal long- and short axis & End-diastolic & 20 \\
\hline 8 & Cuba & 250 & 185 & $6.6(2.8)$ & 65 & $4.7(2.3)$ & 50 & Parasternal long- and short axis & End-systolic & 21 \\
\hline 49 & Canada & 40 & 20 & $12.9(2.7)$ & 20 & $8.4(2.5)$ & NA & Parasternal long- and short axis & End- systolic & 15 \\
\hline 45 & Turkey & 64 & 34 & $6.43(0.9)$ & 30 & $5.35(0.75)$ & 50 & $\begin{array}{l}\text { Long-axis and apical four- } \\
\text { chamber }\end{array}$ & End- diastolic & 22 \\
\hline 46 & Mexico & 153 & 119 & $5.39(1.75)$ & 34 & $4(1.67)$ & 50 & Parasternal long- and short axis & End- systolic & 22 \\
\hline 48 & Japan & 311 & 166 & $5(2.1)$ & 145 & $4.4(2.3)$ & 75 & Parasternal long- and short axis & End- systolic & 21 \\
\hline 43 & India & 549 & 464 & $5.1(1.06)$ & 85 & $4.63(1.01)$ & 50 & Parasternal long-axis & End- systolic & 16 \\
\hline
\end{tabular}

* Defined percent of stenosis based on angiography for diagnosis of CAD

\subsection{Epicardial fat thickness}

The maximum EFT reported by echocardiography was $12.9 \pm 2.7 \mathrm{~mm}$ in the CAD group and $8.4 \pm 2.5 \mathrm{~mm}$ in the nonCAD group (49). The minimum EFT reported by echocardiography was $2.2 \pm 1.8 \mathrm{~mm}$ in the CAD group and $1.8 \pm 1.4$ $\mathrm{mm}$ in the non-CAD group (6). The EFT was evaluated at the end-systolic stage in 10 studies and the end-diastolic phase in three studies (Table 1). Also, the EFT was achieved by the long- and short-axis approach in eight studies, while by the long-axis approach in four studies and by long-axis and apical four-chamber alone in one study (Table 1).

\subsection{Meta-analysis}

The heterogeneity was found among the researched studies $\left(\mathrm{I}^{2}=91.8 \%, \mathrm{p}=0.000, \mathrm{Q}\right.$-value $\left.=146.43, \mathrm{df}[\mathrm{Q}]=12\right)$ using the random effect model. The patients with CAD had a significantly higher echocardiographic EFT than those without $\mathrm{CAD}$ ( $\mathrm{SMD}=1.03,95 \% \mathrm{CI}=0.70-1.37, \mathrm{p}=0.000$, Figure 2). Sub-group meta-analysis was used to find possible sources of heterogeneity. However, the homogeneity was observed in none of the subgroups of the studies based on the echocardiographic view, the EFT measurement interval, the criteria used to define the CAD based on the percentage of coronary artery stenosis, and quality of studies based on MINORS (Table 2).

\subsection{Publication bias}

The findings of the classic-fail-safe $\mathrm{N}$ analysis showed that the number of missing studies resulting in a higher Pvalue was 1,162. According to Orwin's fail-safe $\mathrm{N}$ analysis, 3,436 other studies were needed to observe no longer significant difference in the mean EFT between the two groups with and without CAD. Based on the Duval and Tweedie's trim-and-fill method, no missing studies were seen on the left and right sides of mean effect. 
Table 2. Subgroup analysis on studies included in the meta-analysis in relation to echocardiographic epicardial fat thickness (EFT) between patients with or without coronary artery disease (CAD)

\begin{tabular}{|l|l|l|l|l|l|l|l|}
\hline Subgroup & Condition & $\begin{array}{l}\text { Studies } \\
(\mathrm{n})\end{array}$ & SMD & $\begin{array}{l}95 \% \\
\text { Confidence } \\
\text { interval }\end{array}$ & $\mathrm{p}^{- \text {-value }}$ & $\mathrm{I}^{2}$ & Q-value \\
\hline \multirow{2}{*}{$\begin{array}{l}\text { Stenosis \% (angiographic } \\
\text { CAD) }\end{array}$} & $50 \%$ & 10 & 1.11 & $0.71-1.51$ & 0.001 & 91.7 & 108.49 \\
\hline & $75 \%$ & 2 & 1.40 & $0.14-0.66$ & 0.002 & 60.49 & 2.54 \\
\hline \multirow{2}{*}{ Echocardiographic view } & $\begin{array}{l}\text { Parasternal long- and } \\
\text { short axis }\end{array}$ & 8 & 0.66 & $0.55-0.78$ & 0.001 & 91.98 & 87.29 \\
\cline { 2 - 8 } & Parasternal long axis & 4 & 0.96 & $0.89-1.31$ & 0.001 & 93.58 & 46.73 \\
\hline \multirow{2}{*}{$\begin{array}{l}\text { Time of EFT } \\
\text { measurement }\end{array}$} & End-diastolic & 4 & 1.09 & $0.26-1.92$ & 0.001 & 94.3 & 52.63 \\
\cline { 2 - 8 } & End-systolic & 9 & 1.00 & $0.64-1.36$ & 0.001 & 90.88 & 87.8 \\
\hline \multirow{2}{*}{ Quality score (MINOR) } & $\geq 20$ & 9 & 1.22 & $0.79-1.64$ & 0.001 & 91.79 & 97.49 \\
\cline { 2 - 8 } & $<20$ & 4 & 0.56 & $0.16-0.96$ & 0.001 & 83.44 & 18.18 \\
\hline
\end{tabular}

Study

\begin{tabular}{lcc}
\hline & $\begin{array}{c}\text { Std diff } \\
\text { in means }\end{array}$ & $\begin{array}{c}\text { Standard } \\
\text { error }\end{array}$ \\
Chaowalit, 2006 & 0.033 & 0.174 \\
Yun, 2009 & 1.179 & 0.176 \\
Eroglu, 2009 & 1.908 & 0.205 \\
Mustelier, 2011 & 0.709 & 0.148 \\
Shemirani, 2011 & 0.538 & 0.121 \\
lacobellis, 2011 & 1.729 & 0.371 \\
Hasan Kaya, 2013 & 1.296 & 0.275 \\
Yañez-Rivera, 2014 & 0.802 & 0.200 \\
Hirata, 2015 & 0.273 & 0.114 \\
Sinha, 2016 & 0.447 & 0.119 \\
Ghaderi, 2016 & 1.357 & 0.225 \\
Meenakshi, 2016 & 1.573 & 0.229 \\
Erkan, 2016 & 2.001 & 0.215 \\
& 0.780 & 0.047
\end{tabular}

Statistics for each study

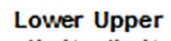

Variance limit limit Z-Value p-Value

\begin{abstract}
$\begin{array}{lllll}0.030 & -0.308 & 0.374 & 0.189 & 0.850\end{array}$
\end{abstract}
$\begin{array}{llllll}0.031 & 0.834 & 1.524 & 6.695 & 0.000\end{array}$

$\begin{array}{llllll}0.042 & 1.506 & 2.310 & 9.295 & 0.000\end{array}$

$\begin{array}{lllll}0.022 & 0.420 & 0.998 & 4.802 & 0.000\end{array}$

$\begin{array}{llllll}0.015 & 0.301 & 0.775 & 4.450 & 0.000\end{array}$

$\begin{array}{llllll}0.137 & 1.003 & 2.456 & 4.666 & 0.000\end{array}$

$\begin{array}{llllll}0.076 & 0.756 & 1.836 & 4.706 & 0.000\end{array}$

$\begin{array}{llllll}0.040 & 0.411 & 1.194 & 4.015 & 0.000\end{array}$

$\begin{array}{llllll}0.013 & 0.049 & 0.497 & 2.393 & 0.017\end{array}$

$\begin{array}{llllll}0.014 & 0.214 & 0.679 & 3.761 & 0.000\end{array}$

$\begin{array}{llllll}0.051 & 0.916 & 1.798 & 6.036 & 0.000\end{array}$

$\begin{array}{llllll}0.052 & 1.125 & 2.022 & 6.875 & 0.000\end{array}$

$\begin{array}{llllll}0.046 & 1.579 & 2.423 & 9.295 & 0.000\end{array}$

$\begin{array}{llllll}0.002 & 0.688 & 0.871 & 16.664 & 0.000\end{array}$

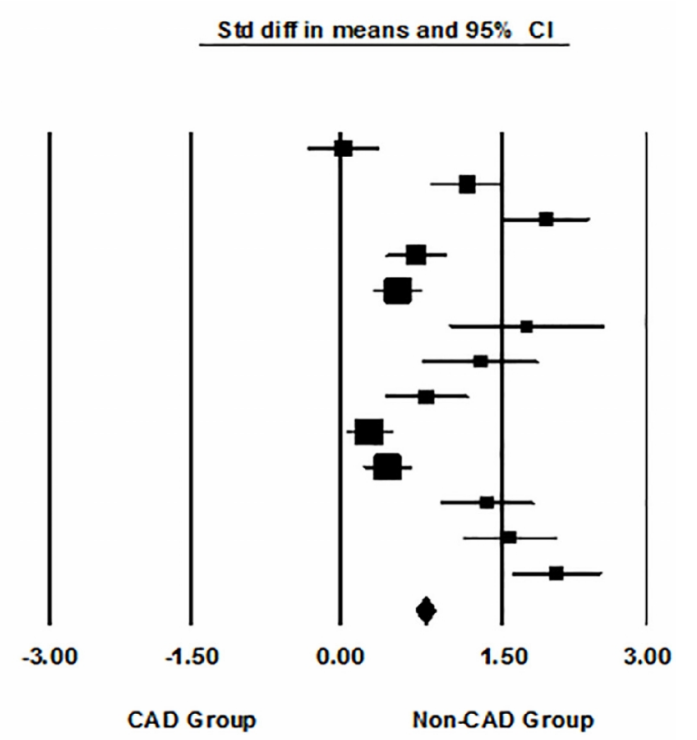

CAD Group

Non-CAD Group

Figure 2. Forest plot showing standard mean difference (SMD) in means and $95 \%$ CI of echocardiographic epicardial fat thickness (EFT) between patients with or without coronary artery disease (CAD) for each study and for the overall analysis.

\section{Discussion}

\subsection{Summary of main results}

The current meta-analysis showed that the echocardiographic EFT was significantly higher in the CAD patients compared to non-CAD ones. The findings of this study demonstrated that the echocardiography could also show higher EFT in relation to CAD, like other imaging interventions.

\subsection{Comparison with other Meta-analysis}

Our study was the first meta-analysis to evaluate EFT measured by echocardiography in association with CAD. To date, three other meta-analyses have examined the relationship between EFT and CAD, although there are two critical differences between them and our study (9-11). First, the relationship between the CAD and the EFT measured by various methods such as CT scan, echocardiography and MRI was examined in the first and second meta-analyses, while we believed that the diagnostic accuracy of CT scan and MRI differs from echocardiography, and therefore their findings cannot necessarily match what was achieved through echocardiography $(9,10)$. Apart from the high cost of using CT scan and MRI, and receiving massive amounts of radiation in CT scans, these images should sometimes be produced with contrast media whose application is limited in patients with renal dysfunction or with a history of allergic reactions $(52,53)$. On the other hand, it is impossible to perform CT scan and MRI in many developing countries and echocardiography is the only possible cardiac imaging modality; therefore, we believe that performing a meta-analysis on echocardiographic findings alone will be more valuable and more practical, especially in areas with limited facilities. The third meta-analysis (11) performed on the relationship between EFT 
and CAD containing articles up to 2016 carried out only those studies that examined the EFT measured by CT scans regarding $\mathrm{CAD}$, and there was no evidence on the echocardiographic EFT. However, the common point among the meta-analyses conducted over the past years with our study was that EFT had been reported higher in CAD patients compared to non-CAD patients in all studies. Although, other meta-analyses evaluating EFT in relation to metabolic syndrome have also been performed, and their findings suggest a higher EFT in patients with metabolic syndrome (54). On the other hand, our meta-analysis was done on thirteen studies, while previous works on EFT and CAD were reported on eight (9) and ten (10) studies, respectively, with the sample size of 1,383 and 1,525, whereas our study included thirteen studies with a total sample size of 2,436, about 1,000 more than previous meta-analyses. However, only one of the two similar meta-analyses in this field evaluated a subgroup of analyses on studies computing EFT by echocardiography, and the results among the six studies showed that the SMD value was 0.98 (95\% $\mathrm{CI}=0.43-1.53, \mathrm{p}=0.002)$, approximately equal to our study (10). However, it should be noted that $95 \%$ confidence interval in our study estimated a much smaller range compared to the findings from the Wu et al. study (10), due to the statistical sample size in our study being almost more than twice as high. Therefore, in contrast to the study of $\mathrm{Wu}$ et al., who reported an uncertain association between echocardiographic EFT in the right ventricular free wall and CAD, our findings showed a nearly definite association between echocardiographic EFT and CAD, with higher generalizability.

\subsection{Causes of heterogeneity}

The Chi-square test result in our study was about 146 with the P-value less than 0.05 , meaning that the differences in the results are non-randomized and statistically significant. Also, the $\mathrm{I}^{2}$ index in our study was found to be $92 \%$, indicating the presence of sources for study heterogeneity. Given the obtained heterogeneity, we used the random effect model in this study. However, we conducted a subgroup analysis to find the possible source of heterogeneity among various factors such as the echocardiographic view, the EFT measurement interval, and the criteria used to define the CAD based on the percentage of coronary artery stenosis and the quality of studies based on MINORS. Before the subgroup analysis, we found that one of the leading causes of heterogeneity between studies was the difference in the echocardiographic view and the end-systolic or end-diastolic time used to calculate EFT, because this difference in these parameters could lead to different measurements of the EFT values. The subgroup analysis results showed that $\mathrm{I}^{2}$ index was over $50 \%$ in all end-systolic or end-diastolic subgroups, as well as in the parasternal long axis view, long- and short-axis, long-axis, and apical four-chamber subgroups. Additionally, operatordependent echocardiographic EFT measurement was another potential factor related to heterogeneity that could not be evaluated in the current study. Moreover, one of the possible sources that could not be considered in our study was the status of the patient's race. The studies included in our meta-analysis were conducted in nine different countries, but the effect of race on heterogeneity was not measurable due to failing to report the racial status of the subjects under study. In addition, the body mass index and age were also other possible sources of heterogeneity whose role was impossible to examine as the sources of heterogeneity due to the lack of reference to them in the majority of studies.

\subsection{Publication bias and quality of evidence}

The sensitivity analysis in our meta-analysis indicated that no study had a significant influential effect on overall estimates. Also, our tests revealed that there was no publication bias among the studies, and no missing study was found; therefore, it can be claimed that recent meta-analysis findings have high generalizability. On the other hand, we evaluated the articles qualitatively using a valid checklist. In most studies, the assessment score was reported to be higher than 20 , indicating the desirability of quality in the studies.

\subsection{Why Epicardial fat thickness is important}

EFT has a higher ability to absorb and secrete free fatty acids, compared with other visceral fat deposits, and is known to be a source for adipokines and other signaling molecules that are important for cardiac development but can also play a role in inflammation and atherosclerosis (2). Although there is still no definitive mechanism for the cause of higher EFT in CAD patients, it seems that one of the involved mechanisms can be attributed to reduce the production of adiponectin in the EFT of CAD patients $(55,56)$. On the other hand, the release of constrictor factors such as chemerin, resistin, and angiotensin II also increases in adipocytes $(56,57)$. Additionally, increased epicardial fat deposits can be associated with the expression of a broad range of inflammatory factors such as CCL2, IL-1b, IL6, IL-8 and TNF-a (2). Moreover, the elevation in EFT can be followed by an increase in the number of cells positive for CD11c, which is associated with CAD (48). Also, patients with heart diseases have shown that EFT releases high levels of type II secretory phospholipase A2, thus contributing to the production of inflammatory lipid 
mediators $(2,54,55)$. Meanwhile, high level of type II secretory phospholipase A2, in turn, is known as an independent factor in increasing CAD risk (2).

\subsection{Limitations}

There were multiple limitations in our meta-analysis. Due to numerous inclusion and exclusion criteria and also insufficient information in eight studies, many studies were excluded from our final analysis, resulting in further limitation of the examined samples. Considering these criteria, we tried to control, as far as possible, the sources of known heterogeneity. All studies had an observational design, which has no good position in the value pyramid of studies. Several factors such as age and anthropometric status of individuals can be effective on EFT, but we could not take their effects into account because of the inadequate reporting of these variables in all studies.

\section{Conclusions}

According to the findings of the current meta-analysis, echocardiographic EFT measurement seems to be an acceptable strategy for risk stratification of heart diseases regarding ease of use, cost-effectiveness and non-radiation exposure characteristics compared to other imaging interventions. We believe that conducting future studies aimed at comparing echocardiographic EFT between the two groups with and without CAD alone would be no longer valuable; because increased EFT can be clearly seen in the CAD individuals. Achievement of a certain cut-off point from echocardiographic EFT is likely to be a challenging issue for future diagnosis of CAD, and this could be good grounds for future research. Interestingly, the majority of studies included in our meta-analysis were carried out in Asian and Middle Eastern countries, and few studies are available in European countries to examine the relationship between echocardiographic EFT and CAD. Therefore, it seems that this study design in European countries can effectively help to obtain the association of echocardiographic EFT with CAD. Also, the role of EFT as a prognostic factor has not been well addressed, which could be good grounds for future research.

\section{Acknowledgments:}

The present article has been adapted from a research project (Grant No. 960248) and Thesis in Cardiology Specialty written by Dr. Mohammad Ali Ansari, funded by the Deputy of research at Mashhad University of Medical Sciences, Iran.

\section{Conflict of Interest:}

There is no conflict of interest to be declared.

Authors' contributions:

All authors contributed to this project and article equally. All authors read and approved the final manuscript.

\section{References:}

1) Gaborit B, Sengenes C, Ancel P, Jacquier A, Dutour A. Role of Epicardial Adipose Tissue in Health and Disease: A Matter of Fat? Compr Physiol. 2017; 7(3): 1051-82. doi: 10.1002/cphy.c160034. PMID: 28640452.

2) Chistiakov DA, Grechko AV, Myasoedova VA, Melnichenko AA, Orekhov AN. Impact of the cardiovascular system-associated adipose tissue on atherosclerotic pathology. Atherosclerosis. 2017; 263: 361-8. doi: 10.1016/j.atherosclerosis.2017.06.017. PMID: 28629772.

3) Talman AH, Psaltis PJ, Cameron JD, Meredith IT, Seneviratne SK, Wong DT. Epicardial adipose tissue: far more than a fat depot. Cardiovasc Diagn Ther. 2014; 4(6): 416-29. PMID: 25610800, PMCID: PMC4278038.

4) Ghaderi F, Eshraghi A, Shamloo AS, Mousavi S. Association of Epicardial and Pericardial Fat Thickness with Coronary Artery Disease. Electron Physician. 2016; 8(9): 2982-9. doi: 10.19082/2982. PMID: 27790354, PMCID: PMC5074760.

5) Chaowalit N, Somers VK, Pellikka PA, Rihal CS, Lopez-Jimenez F. Subepicardial adipose tissue and the presence and severity of coronary artery disease. Atherosclerosis. 2006; 186(2): 354-9. doi: 10.1016/j.atherosclerosis.2005.08.004. PMID: 16183065.

6) Yun KH, Rhee SJ, Yoo NJ, Oh SK, Kim NH, Jeong JW, et al. Relationship between the Echocardiographic Epicardial Adipose Tissue Thickness and Serum Adiponectin in Patients with Angina. J Cardiovasc Ultrasound. 2009; 17(4): 121-6. doi: 10.4250/jcu.2009.17.4.121. PMID: 20661336, PMCID: PMC2889395.

7) Eroglu S, Sade LE, Yildirir A, Bal U, Ozbicer S, Ozgul AS, et al. Epicardial adipose tissue thickness by echocardiography is a marker for the presence and severity of coronary artery disease. Nutr Metab Cardiovasc Dis. 2009; 19(3): 211-7. doi: 10.1016/j.numecd.2008.05.002. PMID: 18718744. 
8) Mustelier JV, Rego JOC, González AG, Sarmiento JCG, Riverón BV. Echocardiographic parameters of epicardial fat deposition and its relation to coronary artery disease. Arquivos brasileiros de cardiologia. 2011; 97(2): 122-9. doi: 10.1590/S0066-782X2011005000068. PMID: 21655877.

9) $\mathrm{Xu} \mathrm{Y,} \mathrm{Cheng} \mathrm{X,} \mathrm{Hong} \mathrm{K,} \mathrm{Huang} \mathrm{C,} \mathrm{Wan} \mathrm{L.} \mathrm{How} \mathrm{to} \mathrm{interpret} \mathrm{epicardial} \mathrm{adipose} \mathrm{tissue} \mathrm{as} \mathrm{a} \mathrm{cause} \mathrm{of}$ coronary artery disease: a meta-analysis. Coron Artery Dis. 2012; 23(4): 227-33. doi: 10.1097/MCA.0b013e328351ab2c. PMID: 22361934.

10) Wu FZ, Chou KJ, Huang YL, Wu MT. The relation of location-specific epicardial adipose tissue thickness and obstructive coronary artery disease: systemic review and meta-analysis of observational studies. BMC Cardiovasc Disord. 2014; 14: 62. doi: 10.1186/1471-2261-14-62. PMID: 24884458, PMCID: PMC4101835.

11) Mancio J, Azevedo D, Saraiva F, Azevedo AI, Pires-Morais G, Leite-Moreira A, et al. Epicardial adipose tissue volume assessed by computed tomography and coronary artery disease: a systematic review and meta-analysis. Eur Heart J Cardiovasc Imaging. 2018; 19(5): 490-7. PMID: 29236951.

12) Moher D, Shamseer L, Clarke M, Ghersi D, Liberati A, Petticrew M, et al. Preferred reporting items for systematic review and meta-analysis protocols (PRISMA-P) 2015 statement. Systematic reviews. 2015; 4: 1. doi: 10.1186/2046-4053-4-1. PMID: 25554246, PMCID: PMC4320440.

13) Slim K, Nini E, Forestier D, Kwiatkowski F, Panis Y, Chipponi J. Methodological index for nonrandomized studies (minors): development and validation of a new instrument. ANZ J Surg. 2003; 73(9): 712-6. doi: 10.1046/j.1445-2197.2003.02748.x. PMID: 12956787.

14) Wu FZ, Wu CC, Kuo PL, Wu MT. Differential impacts of cardiac and abdominal ectopic fat deposits on cardiometabolic risk stratification. BMC Cardiovasc Disord. 2016; 16: 20. doi: 10.1186/s12872-016-01955. PMID: 26800881, PMCID: PMC4724070.

15) Maimaituxun G, Shimabukuro M, Fukuda D, Yagi S, Hirata Y, Iwase T, et al. Local Thickness of Epicardial Adipose Tissue Surrounding the Left Anterior Descending Artery Is a Simple Predictor of Coronary Artery Disease- New Prediction Model in Combination With Framingham Risk Score. Circ J. 2018; 82(5): 1369-78. doi: 10.1253/circj.CJ-17-1289. PMID: 29563352.

16) Austys D, Bulotaite E, Valevičienė NR, Stukas R. Epikardinio riebalinio audinio tūrio bei storio skirtumai tarp patyrusių miokardo infarktą ir širdies bei kraujagyslių ligomis nesiskundžiančių asmenų. Sveikatos mokslai. 2015; 25(3): 41-7. doi: 10.5200/sm-hs.2015.048.

17) Wu FZ, Huang YL, Wang YC, Lin HS, Chen CS, Ju YJ, et al. Impact of location of epicardial adipose tissue, measured by coronary artery calcium-scoring computed tomography on obstructive coronary artery disease. American Journal of Cardiology. 2013; 112(7): 943-9. doi: 10.1016/j.amjcard.2013.05.022. PMID: 23809622.

18) Kim HM, Kim KJ, Lee HJ, Yu HT, Moon JH, Kang ES, et al. Epicardial adipose tissue thickness is an indicator for coronary artery stenosis in asymptomatic type 2 diabetic patients: its assessment by cardiac magnetic resonance. Cardiovascular diabetology. 2012; 11(1): 83. doi: 10.1186/1475-2840-11-83. PMID: 22809408, PMCID: PMC3461492.

19) Bastarrika G, Broncano J, Schoepf UJ, Schwarz F, Lee YS, Abro JA, et al. Relationship between coronary artery disease and epicardial adipose tissue quantification at cardiac CT: comparison between automatic volumetric measurement and manual bidimensional estimation. Academic radiology. 2010; 17(6): 727-34. doi: 10.1016/j.acra.2010.01.015. PMID: 20363161.

20) Wang TD, Lee WJ, Shih FY, Huang CH, Chen WJ, Lee YT, et al. Association of epicardial adipose tissue with coronary atherosclerosis is region-specific and independent of conventional risk factors and intraabdominal adiposity. Atherosclerosis. 2010; 213(1): 279-87. doi: 10.1016/j.atherosclerosis.2010.07.055. PMID: 20801451.

21) Hwang IC, Park HE, Choi SY. Epicardial adipose tissue contributes to the development of non-calcified coronary plaque: a 5-year computed tomography follow-up study. J Atheroscler Thromb. 2017; 24(3): 26274. doi: 10.5551/jat.36467. PMID: 27506880, PMCID: PMC5383543.

22) Picard FA, Gueret P, Laissy JP, Champagne S, Leclercq F, Carrie D, et al. Epicardial adipose tissue thickness correlates with the presence and severity of angiographic coronary artery disease in stable patients with chest pain. PloS One. 2014; 9(10): e110005. doi: 10.1371/journal.pone.0110005. PMID: 25335187, PMCID: PMC4204866.

23) Bachar GN, Dicker D, Kornowski R, Atar E. Epicardial adipose tissue as a predictor of coronary artery disease in asymptomatic subjects. American Journal of Cardiology. 2012; 110(4): 534-8. doi: 10.1016/j.amjcard.2012.04.024. PMID: 22579086. 
24) Yüce G, Türkvatan A, Yener Ö. Can aortic atherosclerosis or epicardial adipose tissue volume be used as a marker for predicting coronary artery disease? Journal of cardiology. 2015; 65(2): 143-9. doi: 10.1016/j.jjcc.2014.03.017. PMID: 24954286.

25) Kim SH, Chung JH, Kwon BJ, Song SW, Choi WS. The associations of epicardial adipose tissue with coronary artery disease and coronary atherosclerosis. Int Heart J. 2014; 55(3): 197-203. doi: 10.1536/ihj.13-303. PMID: 24806380.

26) Zehir R, Güner A, Hayiroglu MI, Oz TK, Osken A, Aksu H, et al. The clinical usefulness of epicardial adipose tissue in patients with high-intermediate pre-test probability for coronary artery disease. Kardiol Pol. 2018. doi: 10.5603/KP.a2018.0054. PMID: 29399757.

27) Reddy RP, Shetty RK, Raman VG, Nayar S, Shetty K. Correlation of echocardiographic epicardial fat thickness with severity of coronary artery disease: An observational study. Heart Rhythm. 2014; 66: S59. doi: 10.1016/j.ihj.2014.10.164.

28) Ahn SG, Lim HS, Joe DY, Kang SJ, Choi BJ, Choi SY, et al. Relationship of epicardial adipose tissue by echocardiography to coronary artery disease. Heart. 2008; 94(3): e7. doi: 10.1136/hrt.2007.118471. PMID: 17923467.

29) Sen F, Yilmaz S, Sen Ö, Balc KG, Duman İ, Topaloglu S, et al. Epicardial adipose tissue is related to coronary collateral vessel formation in patients with acute coronary syndrome. Scandinavian Cardiovascular Journal. 2015; 49(3): 130-5. doi: 10.3109/14017431.2015.1023345. PMID: 25752649.

30) Tachibana M, Miyoshi T, Osawa K, Toh N, Oe H, Nakamura K, et al. Measurement of epicardial fat thickness by transthoracic echocardiography for predicting high-risk coronary artery plaques. Heart and vessels. 2016; 31(11): 1758-66. doi: 10.1007/s00380-016-0802-5. PMID: 26833041.

31) Tran T, Small G, Cocker M, Yam Y, Chow BJ. A single slice measure of epicardial adipose tissue can serve as an indirect measure of total epicardial adipose tissue burden and is associated with obstructive coronary artery disease. European Heart Journal-Cardiovascular Imaging. 2013; 15(4): 423-30. doi: 10.1093/ehjci/jet175. PMID: 24107904.

32) Bhuiyan G, Roy G, Siddique M, Rahman M, Ahmed K, Nahar F. Relationship between Echocardiographic Epicardial Adipose Tissue (EAT) Thickness and Angiographically Detected Coronary Artery Disease. Mymensingh Med J. 2017; 26(3): 498-504. PMID: 28919601.

33) Nabati M, Saffar N, Yazdani J, Parsaee MS. Relationship between epicardial fat measured by echocardiography and coronary atherosclerosis: a single-blind historical cohort study. Echocardiography. 2013; 30(5): 505-11. doi: 10.1111/echo.12083. PMID: 23305488.

34) Jeong JW, Jeong MH, Yun KH, Oh SK, Park EM, Kim YK, et al. Echocardiographic Epicardial Fat Thickness and Coronary Artery Disease. Circulation Journal. 2007; 71(4): 536-9. doi: 10.1253/circj.71.536.

35) Nishio S, Kusunose K, Yamada H, Hirata Y, Ise T, Yamaguchi K, et al. Echocardiographic epicardial adipose tissue thickness is associated with symptomatic coronary vasospasm during provocative testing. Journal of the American Society of Echocardiography. 2017; 30(10): 1021-7.

36) Ulucan S, Kaya Z, Efe D, Keser A, Katlandur H, Aygun F, et al. Epicardial fat tissue predicts increased long-term major adverse cardiac event in patients with moderate cardiovascular risk. Angiology. 2015; 66(7): 619-24. doi: 10.1177/0003319714548211. PMID: 25163773.

37) Lu MT, Park J, Ghemigian K, Mayrhofer T, Puchner SB, Liu T, et al. Epicardial and paracardial adipose tissue volume and attenuation-Association with high-risk coronary plaque on computed tomographic angiography in the ROMICAT II trial. Atherosclerosis. 2016; 251: 47-54. doi: 10.1016/j.atherosclerosis.2016.05.033. PMID: 27266821, PMCID: PMC4983201.

38) Ng AC, Goo SY, Roche N, van der Geest RJ, Wang WY. Epicardial Adipose Tissue Volume and Left Ventricular Myocardial Function Using 3-Dimensional Speckle Tracking Echocardiography. Can J Cardiol. 2016; 32(12): 1485-92. doi: 10.1016/j.cjca.2016.06.009. PMID: 27720272.

39) Romijn MA, Danad I, Bakkum MJ, Stuijfzand WJ, Tulevski, II, Somsen GA, et al. Incremental diagnostic value of epicardial adipose tissue for the detection of functionally relevant coronary artery disease. Atherosclerosis. 2015; 242(1): 161-6. doi: 10.1016/j.atherosclerosis.2015.07.005. PMID: 26188540.

40) Mahabadi AA, Lehmann N, Kälsch H, Robens T, Bauer M, Dykun I, et al. Association of epicardial adipose tissue with progression of coronary artery calcification is more pronounced in the early phase of atherosclerosis: results from the Heinz Nixdorf recall study. Cardiovascular Imaging. 2014; 7(9): 909-16. doi: 10.1016/j.jcmg.2014.07.002.

41) Yang C, Li L, Zha Y, Peng Z. Correlation between epicardial adipose tissue and severity of coronary artery stenosis evaluated by 64-MDCT. Clinical imaging. 2016; 40(3): 477-80. doi: 10.1016/j.clinimag.2015.12.003. PMID: 27133690. 
42) Uygur B, Celik O, Ozturk D, Erturk M, Otcu H, Ustabasıoglu FE, et al. The relationship between locationspecific epicardial adipose tissue volume and coronary atherosclerotic plaque burden in type 2 diabetic patients. Kardiologia Polska. 2017; 75(3): 204-12. doi: 10.5603/KP.a2016.0167. PMID: 27958614.

43) Sinha SK, Thakur R, Jha MJ, Goel A, Kumar V, Kumar A, et al. Epicardial Adipose Tissue Thickness and Its Association With the Presence and Severity of Coronary Artery Disease in Clinical Setting: A CrossSectional Observational Study. J Clin Med Res. 2016; 8(5): 410-9. doi: 10.14740/jocmr2468w. PMID: 27081428, PMCID: PMC4817582.

44) Greulich S, Maxhera B, de Wiza DH, Smiris K, Mueller H, Heinrichs J, et al. Secretory products from epicardial adipose tissue of patients with type 2 diabetes induce cardiomyocyte dysfunction. Circulation. 2012; 126(19): 2324-34. doi: 10.1161/CIRCULATIONAHA.111.039586. PMID: 23065384.

45) Kaya H, Ertas F, Oylumlu M, Bilik MZ, Yildiz A, Yuksel M, et al. Relation of epicardial fat thickness and brachial flow-mediated vasodilation with coronary artery disease. J Cardiol. 2013; 62(6): 343-7. doi: 10.1016/j.jjcc.2013.05.009. PMID: 23810068.

46) Yañez-Rivera TG, Baños-Gonzalez MA, Ble-Castillo JL, Torres-Hernandez ME, Torres-Lopez JE, Borrayo-Sanchez G. Relationship between epicardial adipose tissue, coronary artery disease and adiponectin in a Mexican population. Cardiovascular ultrasound. 2014; 12(1): 35. doi: 10.1186/1476-712012-35. PMID: 25200587, PMCID: PMC4163040.

47) Hirata $Y$, Yamada H, Kusunose K, Iwase T, Nishio S, Hayashi S, et al. Clinical Utility of Measuring Epicardial Adipose Tissue Thickness with Echocardiography Using a High-Frequency Linear Probe in Patients with Coronary Artery Disease. J Am Soc Echocardiogr. 2015; 28(10): 1240-6.

48) Shemirani H, Khoshavi M. Correlation of echocardiographic epicardial fat thickness with severity of coronary artery disease-an observational study. Anadolu Kardiyol Derg. 2012; 12(3): 200-5. doi: 10.5152/akd.2012.061.

49) Iacobellis G, Lonn E, Lamy A, Singh N, Sharma AM. Epicardial fat thickness and coronary artery disease correlate independently of obesity. Int J Cardiol. 2011; 146(3): 452-4. doi: 10.1016/j.ijcard.2010.10.117. PMID: 21094545.

50) Meenakshi K, Rajendran M, Srikumar S, Chidambaram S. Epicardial fat thickness: A surrogate marker of coronary artery disease - Assessment by echocardiography. Indian Heart J. 2016; 68(3): 336-41. doi: 10.1016/j.ihj.2015.08.005. PMID: 27316487, PMCID: PMC4911429.

51) Erkan AF, Tanindi A, Kocaman SA, Ugurlu M, Tore HF. Epicardial Adipose Tissue Thickness Is an Independent Predictor of Critical and Complex Coronary Artery Disease by Gensini and Syntax Scores. Tex Heart Inst J. 2016; 43(1): 29-37. doi: 10.14503/THIJ-14-4850. PMID: 27047282, PMCID: PMC4810581.

52) Gholoobi A, Sajjadi SM, Shabestari MM, Eshraghi A, Shamloo AS. The impact of remote ischemic preconditioning on contrast-induced nephropathy in patients undergoing coronary angiography and angioplasty: a double-blind randomized clinical trial. Electronic physician. 2015; 7(8): 1557. doi: 10.19082/1557. PMID: 26816582, PMCID: PMC4725407.

53) Schroeder S, Achenbach S, Bengel F, Burgstahler C, Cademartiri F, de Feyter P, et al. Cardiac computed tomography: indications, applications, limitations, and training requirements: report of a Writing Group deployed by the Working Group Nuclear Cardiology and Cardiac CT of the European Society of Cardiology and the European Council of Nuclear Cardiology. Eur Heart J. 2007; 29(4): 531-56. doi: 10.1093/eurheartj/ehm544. PMID: 18084017.

54) Pierdomenico SD, Pierdomenico AM, Cuccurullo F, Iacobellis G. Meta-analysis of the relation of echocardiographic epicardial adipose tissue thickness and the metabolic syndrome. American Journal of Cardiology. 2013; 111(1): 73-8. doi: 10.1016/j.amjcard.2012.08.044. PMID: 23040591.

55) Iacobellis G, Pistilli D, Gucciardo M, Leonetti F, Miraldi F, Brancaccio G, et al. Adiponectin expression in human epicardial adipose tissue in vivo is lower in patients with coronary artery disease. Cytokine. 2005; 29(6): 251-5. doi: 10.1016/j.cyto.2004.11.002.

56) Karastergiou K, Evans I, Ogston N, Miheisi N, Nair D, Kaski JC, et al. Epicardial adipokines in obesity and coronary artery disease induce atherogenic changes in monocytes and endothelial cells. Arteriosclerosis, thrombosis, and vascular biology. 2010; 30(7): 1340-6. doi: 10.1161/ATVBAHA.110.204719. PMID: 20395594.

57) Langheim S, Dreas L, Veschini L, Maisano F, Foglieni C, Ferrarello S, et al. Increased expression and secretion of resistin in epicardial adipose tissue of patients with acute coronary syndrome. Am J Physiol Heart Circ Physiol. 2010; 298(3): H746-53. doi: 10.1152/ajpheart.00617.2009. PMID: 20061546. 